\title{
Review Article \\ Dispersive Solid Phase Extraction for the Analysis of Veterinary Drugs Applied to Food Samples: A Review
}

\author{
Gabriela Islas, ${ }^{1}$ Israel S. Ibarra, ${ }^{1}$ Prisciliano Hernandez, ${ }^{2}$ Jose M. Miranda, ${ }^{3}$ \\ and Alberto Cepeda ${ }^{3}$ \\ ${ }^{1}$ Área Académica de Química, Universidad Autónoma del Estado de Hidalgo, Carretera Pachuca-Tulancingo Km 4.5, \\ 42076 Pachuca, HGO, Mexico \\ ${ }^{2}$ Área de Energías, Universidad Politécnica de Francisco I. Madero, Domicilio Conocido, 42640 Tepatepec, HGO, Mexico \\ ${ }^{3}$ Departamento de Química Analítica, Nutrición y Bromatología, Facultad de Veterinaria, Universidade de Santiago de Compostela, \\ Pabellón 4 Planta Baja, Campus Universitario, s/n, 27002 Lugo, Spain
}

Correspondence should be addressed to Israel S. Ibarra; isio.uaeh@gmail.com

Received 21 April 2017; Revised 16 August 2017; Accepted 29 August 2017; Published 18 October 2017

Academic Editor: Neil D. Danielson

Copyright (C) 2017 Gabriela Islas et al. This is an open access article distributed under the Creative Commons Attribution License, which permits unrestricted use, distribution, and reproduction in any medium, provided the original work is properly cited.

To achieve analytical success, it is necessary to develop thorough clean-up procedures to extract analytes from the matrix. Dispersive solid phase extraction (DSPE) has been used as a pretreatment technique for the analysis of several compounds. This technique is based on the dispersion of a solid sorbent in liquid samples in the extraction isolation and clean-up of different analytes from complex matrices. DSPE has found a wide range of applications in several fields, and it is considered to be a selective, robust, and versatile technique. The applications of dispersive techniques in the analysis of veterinary drugs in different matrices involve magnetic sorbents, molecularly imprinted polymers, carbon-based nanomaterials, and the Quick, Easy, Cheap, Effective, Rugged, and Safe (QuEChERS) method. Techniques based on DSPE permit minimization of additional steps such as precipitation, centrifugation, and filtration, which decreases the manipulation of the sample. In this review, we describe the main procedures used for synthesis, characterization, and application of this pretreatment technique and how it has been applied to food analysis.

\section{Introduction}

The analysis of veterinary drugs has been a recurrent practice in recent years to ensure food quality and minimize the risks that some chemical compounds could present to human health. Their indiscriminate application in therapeutic and prophylactic purposes can lead to residues in animal tissues and in derived foodstuffs $[1,2]$, inducing problems when consumed such as allergic reactions, hypersensitivity, development bacterial resistance, and in some cases death [3-5].

For these reasons, international organizations, such as the European Commission (EC) and the Food and Drug Administration (FDA), have established maximum residue limits (MRLs) of substances in food samples that are employed for veterinary purposes. The MRL is defined as the acceptable concentration of a substance found in foods of animal origin that are consumed by humans and do not constitute any health risk. In order to prevent the problems caused by excessive use of veterinary drugs, the development of sensitive and robust analytical methodologies has been necessary for the determination of antibiotics residues at $\mu \mathrm{g} \mathrm{Kg}^{-1}$ or $\mu \mathrm{g} \mathrm{L}{ }^{-1}$ levels in foods of animal origin [6-8].

Several analytical methodologies have been developed for the extraction, isolation, clean-up, and preconcentration of residues of veterinary drugs such as liquid-liquid extraction (LLE) [9], solid phase extraction (SPE) [10], solid phase microextraction (SPME) [11], microwave-assisted extraction (MAE) [12], and pressurized liquid extraction (PLE) [13]. However, the use of these techniques in some cases require additional pretreatments or specific manipulations. The classical technique employed for preconcentration and clean-up in the analysis of veterinary drugs is SPE. This technique has allowed the development of alternative methodologies such as dispersive solid phase extraction (DSPE), which is 
based on the addition of a sorbent directly into the analytical solution followed by dispersion favoring the contact between the sorbent and the analytes $[14,15]$. Once the dispersion process is completed, the sorbent, with the analytes retained on its surface, is separated by a mechanical process, such as centrifugation or filtration. The most attractive property of DSPE is the reduction in sample treatment time that allows more samples to be analyzed in a shorter period of time, in addition to simplicity, adaptability, and easy handling in comparison with the traditional techniques [16].

Since its invention, DSPE has been accepted and applied as a clean-up technique due to its versatility, selectivity, and robustness. It has been used in the extraction, isolation, and clean-up of several compounds present in complex matrices, as in the analysis of veterinary drugs, such as anthelmintics [17-19], benzimidazoles (BZDs) [20], nitroimidazoles [21], sulfonamides (SAs) [22, 23], quinolones (QNs) [24], tetracyclines (TCs) [25], nonsteroidal anti-inflammatory drugs (NSAIDs) $[26,27]$, and $\beta 2$-agonists $[28,29]$ present in animal tissues, foodstuffs, lacteous products, and water. Additionally, DSPE has been coupled with several instrumental techniques in the determination and quantification of veterinary drug residues in food samples, such as capillary electrophoresis (CE) coupled with diode-array detection (DAD) [30, 31], ultraviolet detection (UV) [32], and mass spectrometry (MS) [20]; high performance liquid chromatography (HPLC) coupled with ultraviolet detection (UV) [33], fluorescence (FL) [34], and diode-array (DAD) detection [35]; liquid chromatography (LC) coupled with mass spectrometry (MS/MS) [36]; ultra-high performance liquid chromatography (UHPLC) coupled with negative electrospray ionization tandem mass spectrometry (ESI-MS/MS) [37], MS/MS [38], DAD [39], and FL [40]; and ultra-fast liquid chromatography (UFLC) coupled with tandem quadrupole mass spectrometry (MS/MS) [23].

\section{Background and History}

Dispersive solid phase extraction (DSPE) has been a widely used technique since its invention around 2000 [41] and has been successfully applied as a method of extraction, isolation, and cleaning in the analytic treatment of a wide variety of veterinary drugs employed in the livestock industry. DSPE simplifies SPE clean-up, allows more samples to be analyzed at one time, is quite rapid, and requires low solvent consumption. DSPE consists of the addition of a solid sorbent, usually silica or polymer based, directly into the sample solution [14-16]. The dispersion process increases the contact area between the sorbent and the analyte. The sorbents employed in DSPE in the determination of antibiotic residues are solids chemically modified by the addition of several chemical compounds that modify their affinities. These modifications ensure the selectivity for the analytes of interest, which allows the maximal retention, minimizing the interferences in the analytical matrix [28]. After the dispersion, the sorbent is isolated by a centrifugation or filtration process. Once the solid phase is isolated, the analytes or interferences adsorbed on the surface of the sorbent could be easily eluted or eliminated with the addition of adequate organic solvents. Figure 1 shows a scheme of the DSPE procedure [22, 42-47].

DSPE is considered to be a micro- and macroscale method of extraction and cleaning, employed in different analytical methodologies as a procedure for the elimination of potential interferences (clean-up) that could affect the subsequent determination of the analytes [45, 48]. However, one of the critical steps in DSPE is the selection of the sorbent, and it is necessary to consider chemical and physical characteristics that allow maximal interaction between the sorbent and the analytes, ensuring selectivity extraction, removal, or preconcentration of analytes present in analytical matrices [45]. DSPE technique achieves adequate limits of detection (LOD) for the analysis of antibiotics, with the additional advantage of low consumption of solvents in the treatment of the sample. Therefore, it is considered to be a low-cost technique in comparison with classical techniques such as LLE and SPE [22, 44, 47, 49].

The sorbents employed in DSPE are mainly based on silica embedded with several functional groups, such as $\mathrm{Su}-$ pelclean PSA (ethylenediamine-N-propyl) [38, 40, 50, 51], Supelclean- $\mathrm{C}_{18}$ (octadecyl, $\mathrm{C}_{18}$ ), -ethylsilane $\left(\mathrm{C}_{2}\right)$, -aminopropyl $\left(\mathrm{NH}_{2}\right)[45,52]$, that have been previously applied to extraction, clean-up, and even preconcentration process. In this sense, sorbents based on silica are the most used in the extraction process of compounds over a wide range of $\mathrm{pH}$ or in the elimination of interferences present in the food matrix such as organic compounds, dyes, lipids, and proteins [45, 50-52]. On the other hand, sorbents as Z-Sep Supelco and Z-Sep+ have been employed to enhance sample clean-up for complex matrices, their Lewis-acid, Lewis-base interactions, allowing the effective removal of fat and color from sample extracts in comparison with the traditional phases for Quick, Easy, Cheap, Effective, Rugged, and Safe (QuEChERS). This kind of sorbents allows obtaining robust analysis and in some cases could replace the conventional sorbents in several methodologies without additional method development [5355].

These sorbents have been applied in the analysis of several drug residues. In recent years, in order to simplify sample pretreatment and minimize organic solvent consumption, several sorbents have been developed and synthesized with higher affinity, selectivity, and retention capacity. These alternatives in extraction, isolation, and cleanup processes are based on the fundamental principle of DSPE, the dispersion of a sorbent in a sample in solution. These analytical methodologies are QuEChERS [50, 53-56] dispersive micro-solid-phase extraction (DMSPE) [57, 58]. The use of sorbents employed in DSPE coupled with magnetic particles has been denominated as magnetic solid phase extraction (MSPE) [30, 31, 59, 60]. Recently, carbonaceous materials have been used as part of the sorbents composition [24, 37, 39, 58], and molecular imprinted polymers (MIPs) have been the techniques most applied on the pretreatment sample in the antibiotic and drug analysis. Figure 2 shows the basic principles of these techniques, which have been applied successfully for the determination of drug residues $[61,62]$. 


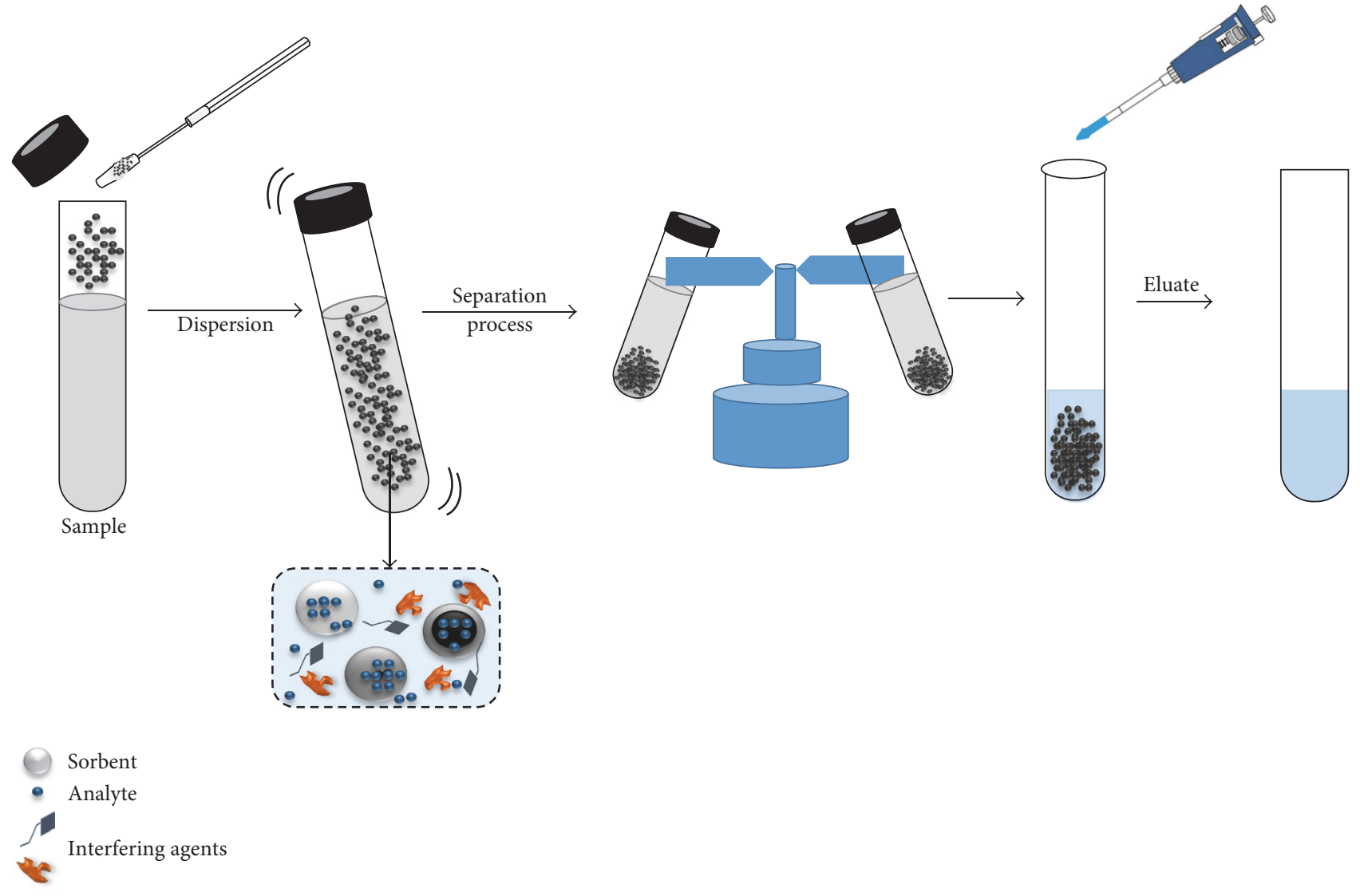

FIGURE 1: Scheme of dispersion methodology by dispersive solid phase extraction.

\section{Solid Sorbents: Types and Characteristics}

In recent years, several sorbents have been developed based on the principle of DSPE and applied to several fields, such as biomedicine, biotechnology, materials science, nanotechnology, and polymer synthesis. These sorbents were synthesized by different processes such as sol-gel process, suspension, precipitation, multistep swelling, and bulk polymerization $[32,36,59,63]$. This new generation of sorbents has been synthesized and applied to MIPs in complex matrices such as agriculture-food samples. The development, design, and synthesis of MIPs are in function of polymerization methods, functional monomer, cross-linking agent, template, porogenic solvent, and the initiator [63-66]. The interactions type according to their structural characteristics are principally electrostatic interactions, hydrogen bonding, Van der Waals forces, hydrophobic and hydrophilic interactions, and dipoledipole bonds [67-73].

In recent decades, the application of polymers has been increasingly developed to make new alternatives that allow the easy isolation of these particles. Since 1988, paramagnetic materials have been implemented in the process of synthesis of sorbents; these solids are mainly obtained by the partial oxidation of iron in basic media [74]. Generally, the magnetic sorbent is obtained by the encapsulation of inorganic magnetic particles with silica and polymeric and carbonaceous materials [18]. This technique is based on the dispersion of a magnetic adsorbent in solution. The magnetic adsorbents with the analytes adsorbed on the surface can be isolated and eluted with the addition of appropriate solvents. This type of technique has been named magnetic solid phase extraction (MSPE).

MSPE sorbents offer the principal advantage in their easy manipulation in the isolation by the application of an external magnetic field without additional steps, like centrifugation and filtration used in traditional techniques. These characteristics provide advantages in the pretreatment process, making it easy, fast, and low-cost, which minimizes the possible loss of the analyte [34, 75-77]. Carbonaceous materials used in DSPE possess special characteristics in their morphology, such as high surface area, particle size, and sorption capacity. These characteristics and their hydrophobic surfaces have allowed their application in several cleanup processes, extraction, and recently in the preconcentration of some analytes under specific conditions [24]. The carbonaceous materials most commonly used in DSPE are carbon nanotubes (CNTs) [24, 38], activated carbon (AC) [38], graphene (GP) [78], and graphene oxide (GO) [58]. Their sorption capacity depends on the analyte nature (special array, size, and their chemical composition). However, using carbonaceous materials, the retention capacity could be 


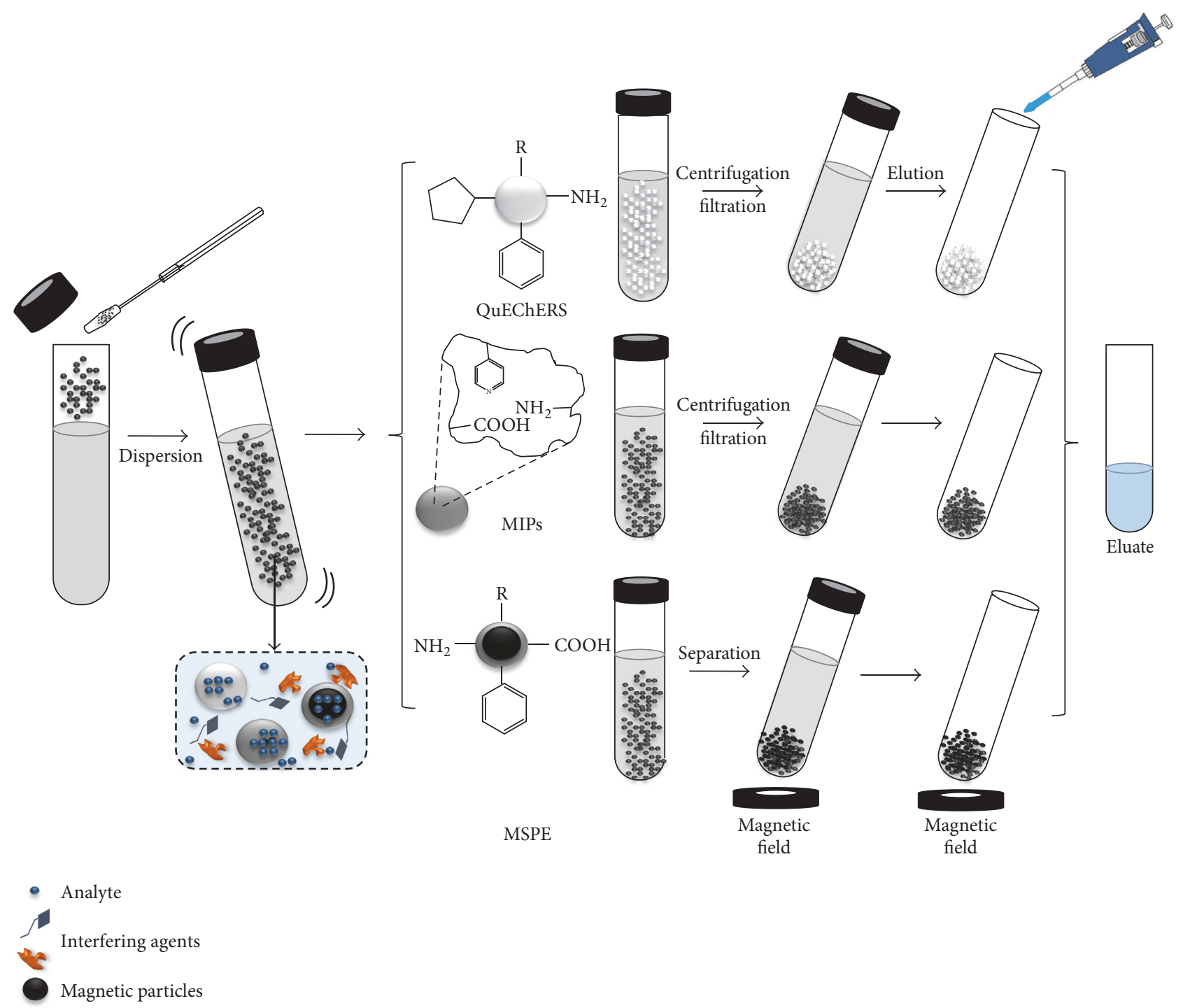

FIGURE 2: Scheme of dispersion solid phase extraction applied for different techniques.

affected by the excess of interferences in the analytical matrix $[26,78]$.

\section{Application of Dispersive Solid Phase Extraction: Analysis of Veterinary Drugs in Food Samples}

The application of DSPE is based on physical and chemical properties of the sorbents and depends on the technique of synthesis employed. It has been used for the extraction and determination of several veterinary drug residues. Table 1 shows several molecular recognition sorbents as pretreatment methods in the determination of anthelmintics [18], clenbuterol (CLB) [79], fluoroquinolones (FQs) [80, 81], quinolones (QNs) [82], sulfonamides (SAs) [23, 83], tetracyclines (TCs) [75], and $\beta$-agonist [34, 73], in both environmental water and food samples [81]. Magnetic solid phase extraction (MSPE) uses a template molecule in the synthesis process, which provides selective mechanisms of recognition based on hydrogen bonding, Van der Waals forces, and dipole-dipole interactions [78-83]. MSPE allows an extraction process that is effective in comparison to the sorbent employed in traditional DSPE, minimizing, in most cases, the number of sample pretreatment steps. MSPE demonstrated a higher affinity for the template molecule allowing obtaining limits of detection in the order of $\mathrm{ng} \mathrm{mL}^{-1}$ with a \% recovery of 63.3 and 124.4 in function of the determination system in the analysis $[68,83]$.

Different from traditional DSPE, MSPE employs an external magnetic field in the extraction process. Table 2 shows important aspects in the use of magnetic particles under MSPE methodology, which is usually employed as a procedure for the extraction, isolation, and preconcentration of analytes from large volumes, eliminating additional steps 


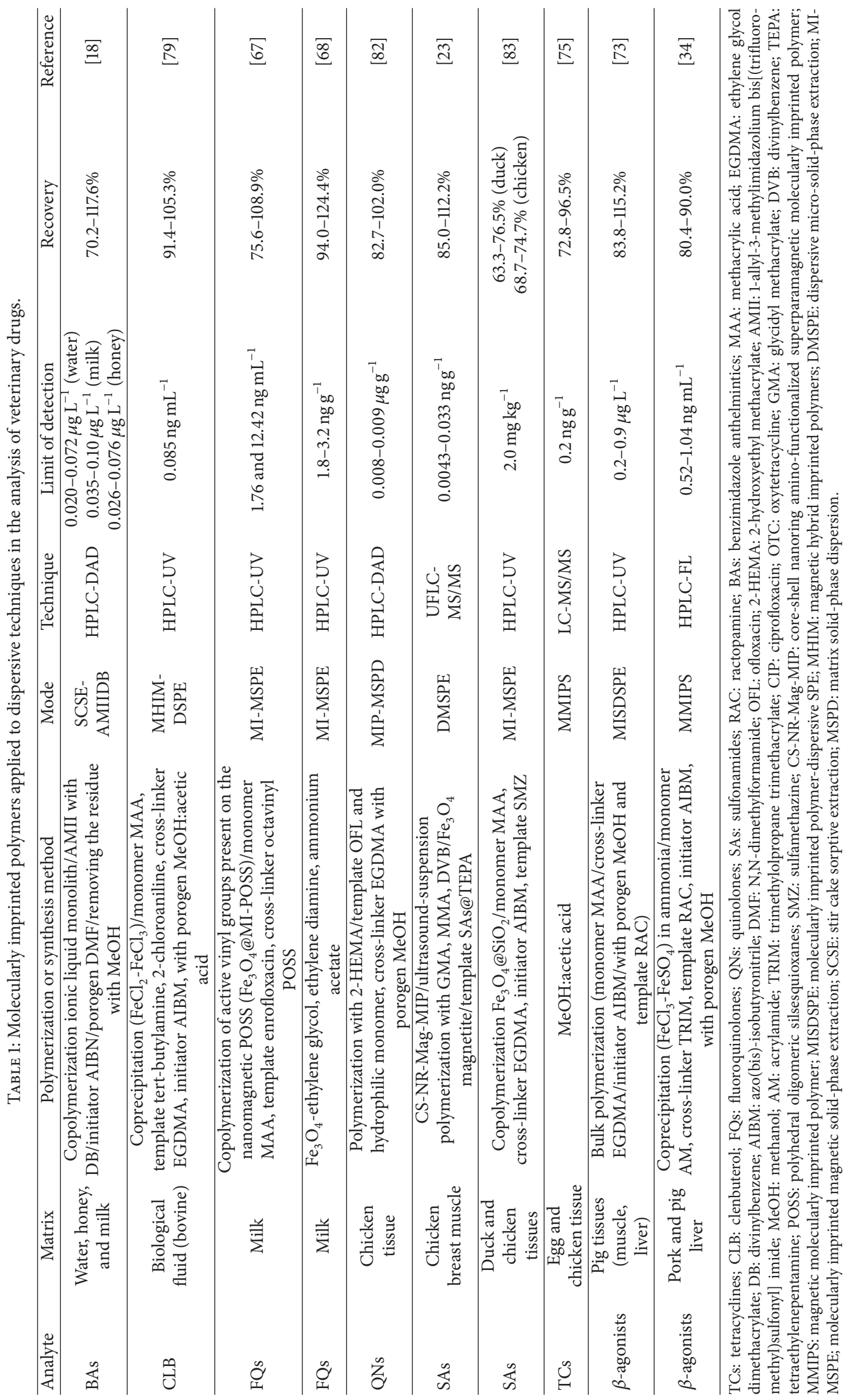




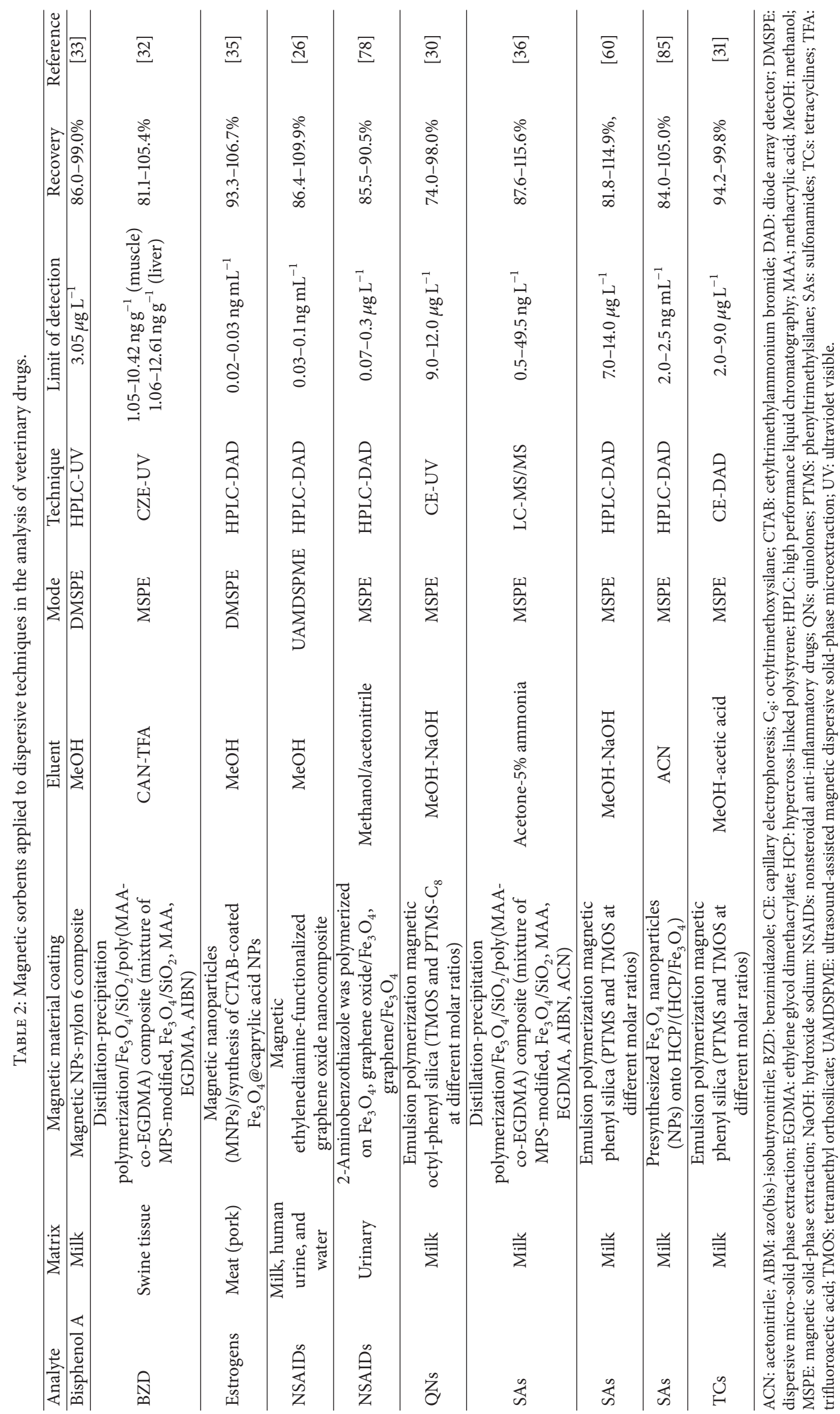


such as centrifugation, precipitation, or filtration of the sample in comparison with the traditional techniques [31, 84].

MSPE was employed for first time in experiments with copper phthalocyanine dye attached to silanized magnetite and magnetic charcoal as sorbents in the separation of safranin $\mathrm{O}$ and crystal violet, with an enrichment of up to 460-fold [31, 32, 36]. Their synthesis process involves the obtaining of magnetite which is coated with silica by the reaction of an alkoxy silane in alkaline solution that allows obtaining sorbents with different morphology and particles size in the order of $\mu \mathrm{m}$ until nm [31].

The method has been used in the extraction and isolation of bisphenol A [33], BZD [32], estrogen [35], NSAIDs [29], QNs [30], SAs [36, 85], and TCs [31] in different matrices such as milk or pork. Subsequently at the isolation process, the analytes can be eluted through organic solvents such as acetonitrile, acetone, or methanol, depending on the solubility of each analyte $[30,31,85]$. The $\%$ recovery obtained by these methods ranges between 74.0 and $115.6 \%$, with limits of detection in the order of $\mu \mathrm{g} \mathrm{L}^{-1}$ and $\mathrm{ng} \mathrm{g}^{-1}$ in their analysis with techniques such as HPLC and CE using UV, DAD, and MS detectors [30, 31, 85].

Table 3 shows the application of dispersion techniques such as DSPME (dispersive solid phase microextraction) [25], DMSPE (dispersive micro-solid-phase extraction) [57], UAE (ultrasound-assisted extraction) [29], and DSPE (dispersive solid phase extraction) with the principal difference in the use of sample volume in the order of $\mathrm{mL}$ and $\mu \mathrm{l}$ during the dispersion step. These types of DSPE employed sorbents coated principally with silica-based $\mathrm{C}_{18}$ and primary and secondary amines for the elimination of interferences present in the food matrix. These sorbents allow selective interactions between them and the analyte $[12,52]$.

However, this process could be affected by interferers present in the analytical matrix, minimizing in some cases the percent retention and subsequent percent recovery. For these reasons, in some cases, additional clean-up steps are necessary to diminish the amount of interferers before analysis of benzimidazole anthelmintic (BAs) [33], bisphenol A [52], nitroimidazoles [21], nitrofurans [86], chloramphenicol [86], QNs [23, 29, 57], TCs [43], SAs [22], and $\beta$-lactams [45]. In the cited works, limits of detection were obtained in the order of $0.03-123 \mu \mathrm{g} \mathrm{kg}^{-1}$ and $0.7-35.5 \mathrm{ng} \mathrm{mL}^{-1}$ in function of the sample, with \% recovery of $58 \%$ in the analysis of $\beta$-lactams until $116 \%$ for nitroimidazoles, nitrofurans, and chloramphenicol.

Other types of sorbents employed in DSPE are based on the addition of carbonaceous materials in the synthesis process. The use of carbonaceous materials such as multiwalled carbon nanotubes (MWCNT) and graphene oxide (GO) has allowed the development of new class of sorbents. The use of MWCNT commercial with different internal diameters and lengths and the use of grapheme (GP) as precursor in the obtaining of GO by Hummers methods and the preparation of OMWCNT allow strong $\pi-\pi$ interactions with analytes that possess doubles bonds, ensuring an adequate analytical selectivity. The amount of these materials in many cases is limited by the cost and the fact that their synthesis method is not always reproducible. For those reasons, the use of carbonaceous materials is usually employed at low amounts [24, 37-39].

Table 4 shows applications focused on the analysis of amantadine, rimantadine, memantine [38], QNs [24], resorcyclic acid lactones [37], and SAs [22, 39, 58] from food samples such as chicken muscle, ground dried feed, pork, milk, honey, and water samples. The use of MWCNT coated with magnetic particles in the extraction of SAs shows a lower $\%$ recovery in comparison with the use of MWCNT that shows in most of the cases \% recovery around of $89.2-117.9 \%$; this could be possible in that the amount of magnetite diminishes the active sites $[22,58]$.

Additionally, the use of O-MWCNT in the synthesis process showed a heterogenic behavior with \% recoveries ranging from $62.3 \%$ to $116 \%$ [24]. However the \% recovery employing GO was 95.3-98.3 in the extraction of sulphadiazine. This could be explained by the number of analytes present in the system and the interaction via $[24,58]$. The use of carbonaceous materials in clean-up process ensures obtaining limits of detection around of $0.15-129 \mu \mathrm{g} \mathrm{kg}^{-1}$ and $0.34-94.0 \mu \mathrm{g} \mathrm{L}^{-1}$ in their coupled techniques such as UHPLC-MS/MS, CE-DAD, UHPLC-DAD, UHPLC-ESIMS/MS, and optimized angled mode-mismatched thermal lens spectroscopy (OAMTLS) [22, 87, 88].

Table 5 shows the use of the QuEChERS technique. This technique has been employed successfully in the analysis of several compounds. It is considered to be a simple technique and has been focused on the analysis of multiresidues of several antibiotic groups of veterinary use by UHPLC-MS/MS and CE-MS in ovine muscle, eggs, milk, honey, fish muscle, chicken muscle, and feedstuffs; the QuEChERS method combines a first simple extraction phase and a second solid phase dispersion step, which allows the removal and clean-up of the analytical matrix using PSA sorbent in the clean-up system. It is considered to be a selective method, quick and cheap in comparison with sorbents modified that require specific synthesis processes for each one. This technique takes into consideration the solid characteristics, sample amount/solvent volume ratios, extraction solvent, and $\mathrm{pH}$ of extraction; the results obtained show recoveries of \% of $56.7-125 \%$ with limits of detection between $0.007-220.8 \mu \mathrm{g} \mathrm{kg}^{-1}$ and 3.0-51.0 $\mu \mathrm{g} \mathrm{L}^{-1}$. Despite the results obtained, QuECheERS method offers advantages in sample treatment, minimizing solvent consumption, sample manipulation, and loss of the analyte and it is also considered environmentally friendly. It also allows obtaining of appropriate detection parameters in the analysis of residues of antibiotics, according to techniques and international regulations [15, 88-95].

\section{Conclusions}

The DSPE technique is based on the dispersion process and employs the use of solid sorbents. It has been used for the retention of several antibiotic families, used in veterinary medicine, that are employed in subtherapeutic doses as growth promoters for foods of animal origin destined for human consumption. This technique is considered to be an effective strategy for the extraction, isolation, and clean-up 


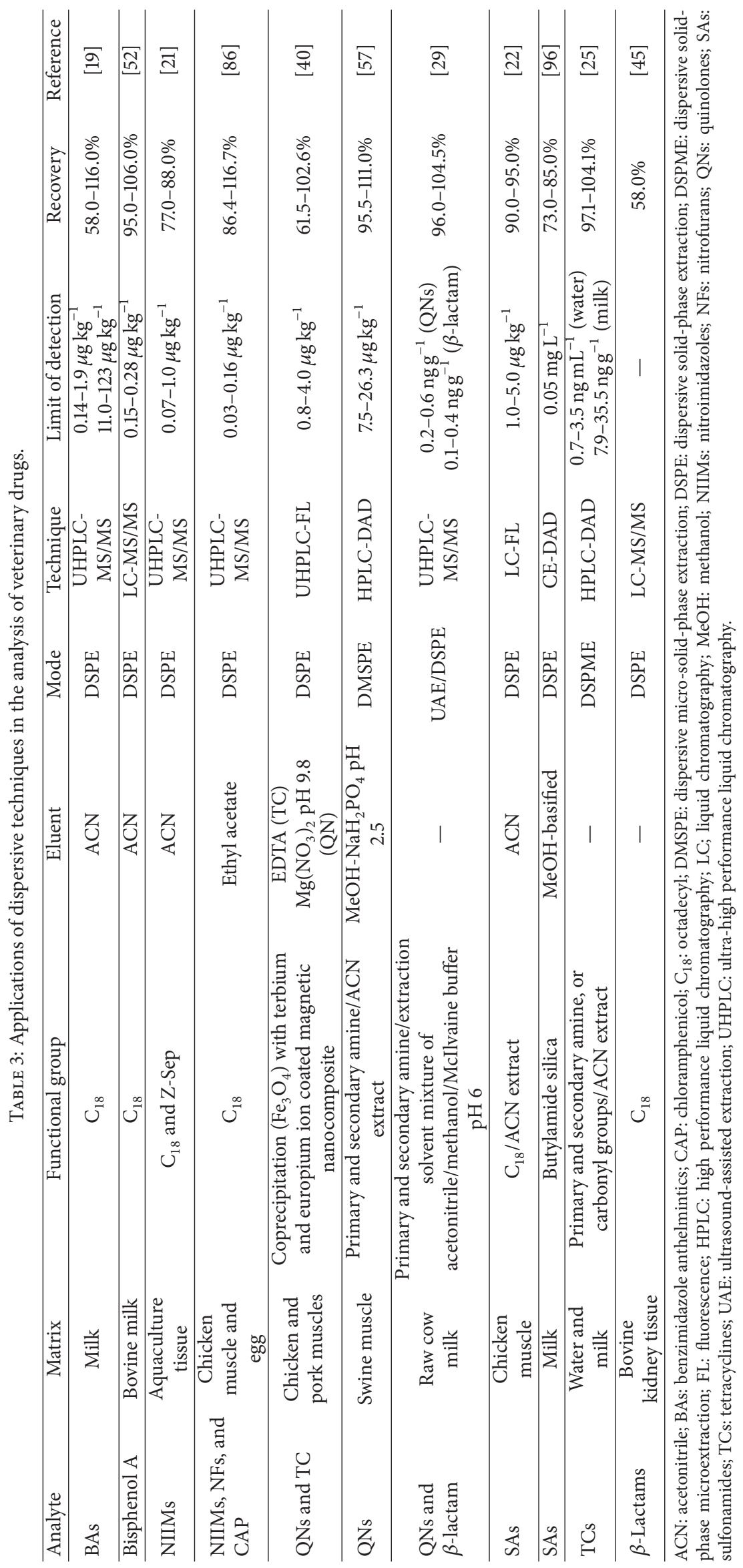




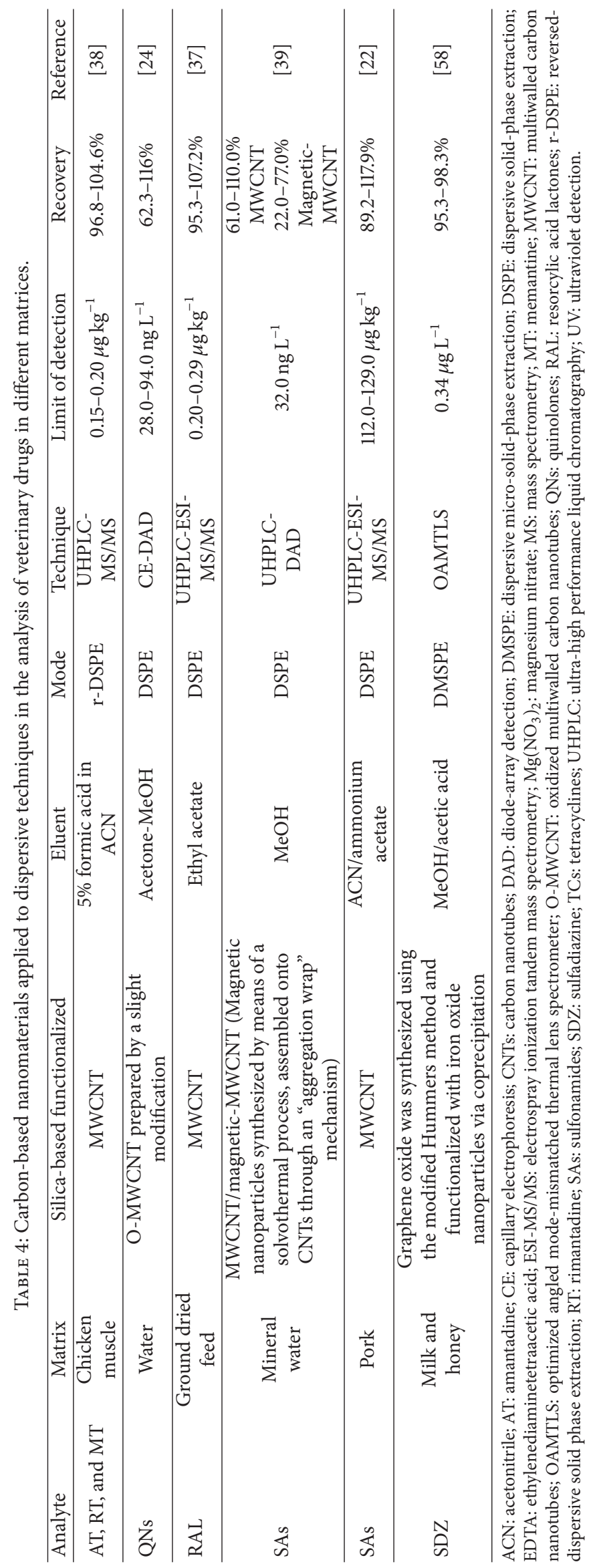




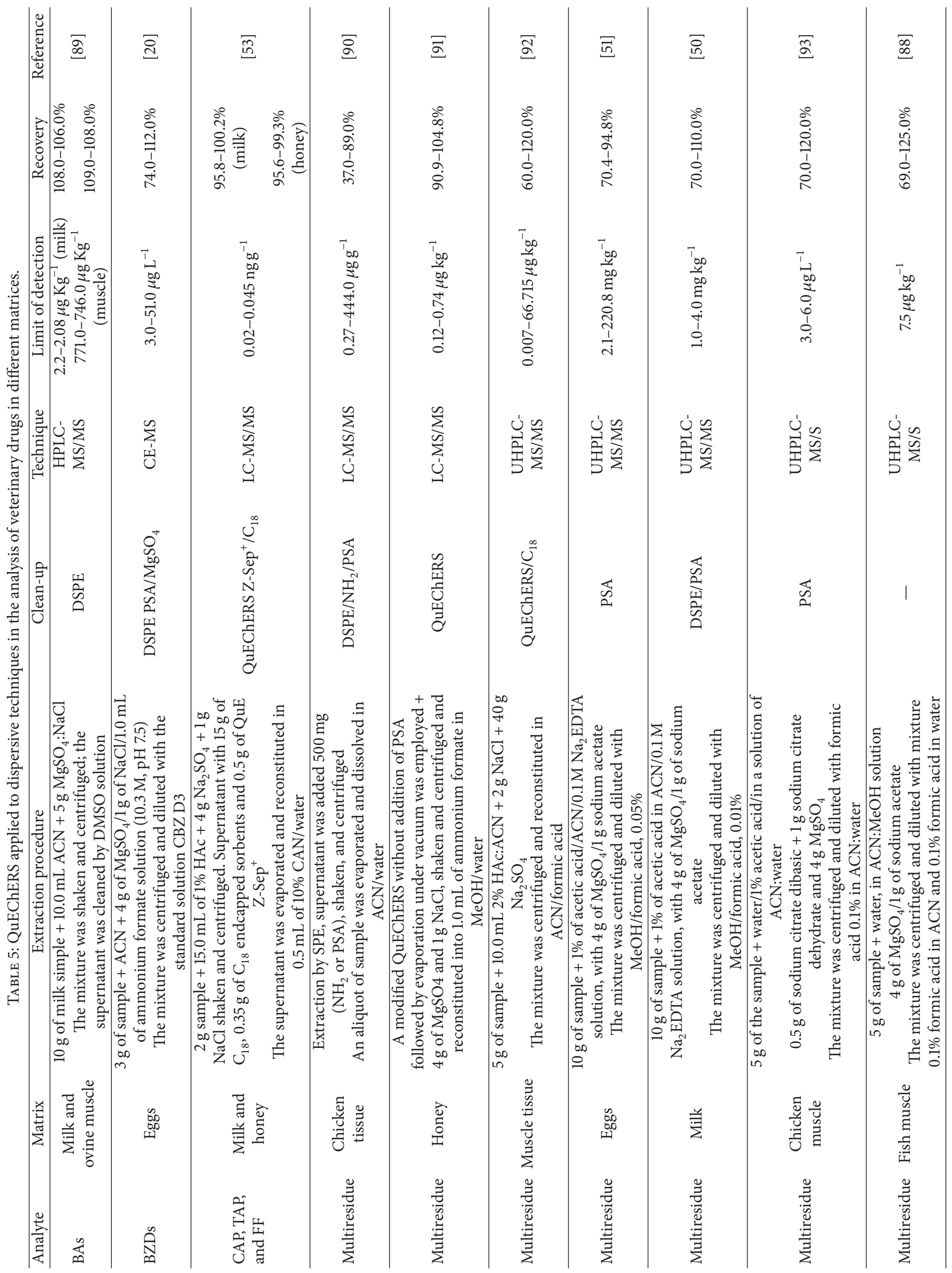




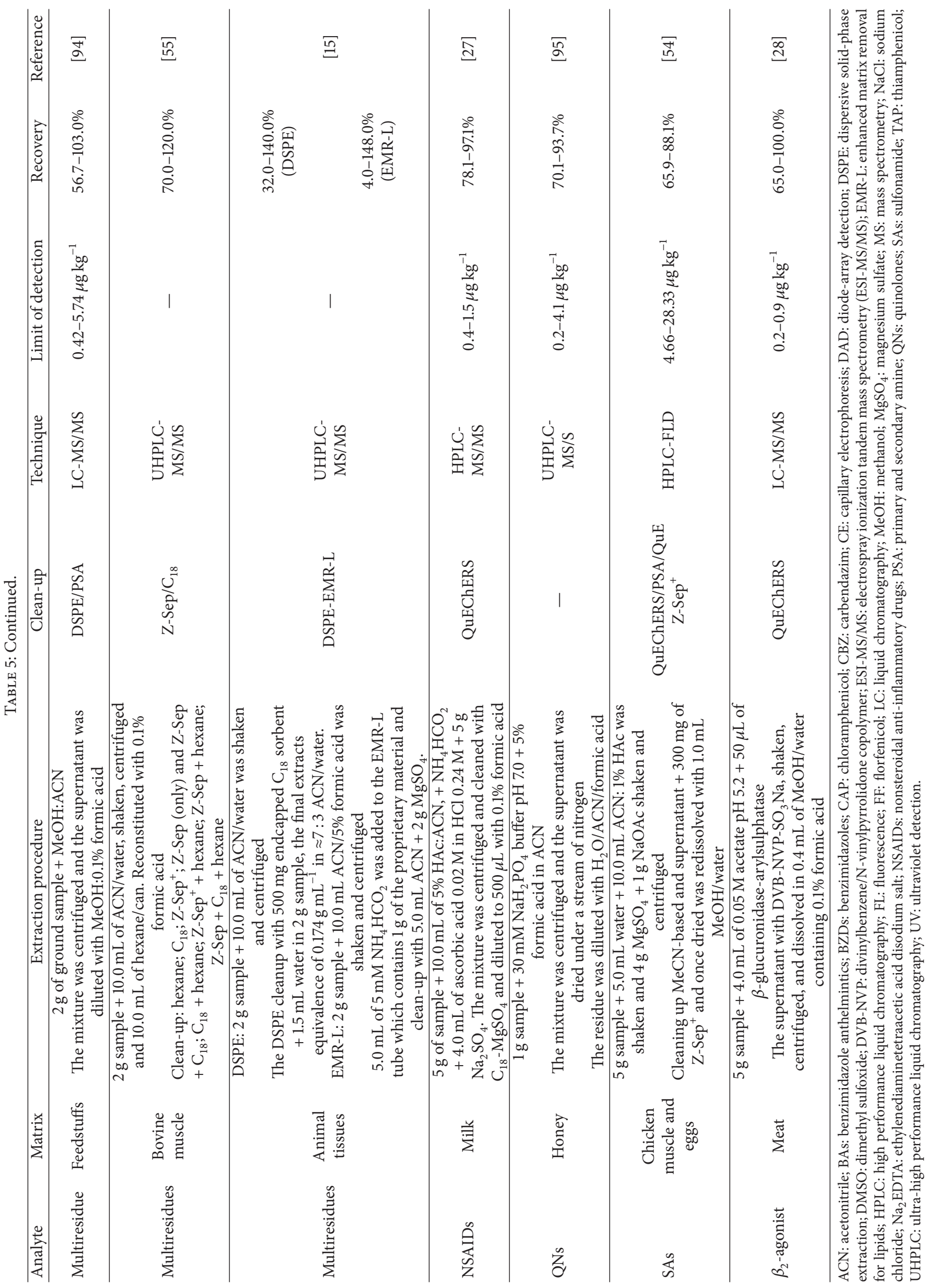


and in a few cases in the preconcentration and analysis of residues in complex matrices. The methodology is employed as a basis for the development and application of analytical methodologies such as QuEChERS and MSPE and minimizes additional steps of centrifugation and filtration compared to other classical methods. In general, the use of dispersive solid sorbents allows more contact between the analyte and sorbent phase, improving the retention of the analyte with the additional advantages of lower solvent consumption and lower cost. In the determination of veterinary drug residues, the use of solid sorbents provides good results in the quantification of antibiotics and provides sensitivity and accuracy sufficient for suitable detection limits. These processes take into account the MRLs established by various international standards.

\section{Conflicts of Interest}

All authors of the present manuscript declare that they have no conflicts of interest.

\section{Acknowledgments}

The authors wish to thank PROMEP for the approved project in the incorporation of new PTC; CONACyT (Project INFR2014-227999 and Retention Grant no. 251112); and Consellería de Cultura, Educacion e Ordenacion Universitaria, Xunta de Galicia (Project EM 2012/153), for financial support.

\section{References}

[1] B. Kinsella, J. O’Mahony, E. Malone et al., "Current trends in sample preparation for growth promoter and veterinary drug residue analysis," Journal of Chromatography A, vol. 1216, no. 46, pp. 7977-8015, 2009.

[2] Y. Wen, M. Zhang, Q. Zhao, and Y.-Q. Feng, "Monitoring of five sulfonamide antibacterial residues in milk by in-tube solidphase microextraction coupled to high-performance liquid chromatography," Journal of Agricultural and Food Chemistry, vol. 53, no. 22, pp. 8468-8473, 2005.

[3] J. Barlow, "Antimicrobial resistance and the use of antibiotics in the dairy industry: Facing consumer perceptions and producer realities," in WCDSAdvances in Dairy Technologies, vol. 23, pp. 47-58, Antimicrobial resistance and the use of antibiotics in the dairy industry, Facing consumer perceptions and producer realities, 2011.

[4] E. R. Gomes and P. Demoly, "Epidemiology of hypersensitivity drug reactions," Current Opinion in Allergy and Clinical Immunology, vol. 5, no. 4, pp. 309-316, 2005.

[5] M. E. Dasenaki and N. S. Thomaidis, "Multi-residue determination of 115 veterinary drugs and pharmaceutical residues in milk powder, butter, fish tissue and eggs using liquid chromatography-tandem mass spectrometry," Analytica Chimica Acta, vol. 880, pp. 103-121, 2015.

[6] R. Ancuceanu, "Maximum Residue Limits of Veterinary Medicinal Products and Their Regulation in European Community Law," European Law Journal, vol. 9, no. 2, pp. 215-240, 2003.

[7] Official Journal of the European Union, vol. L152, 2009.

[8] Official Journal of the European Union, vol. No. 37/2010 of 22, 2009.
[9] L. Jank, M. T. Martins, J. B. Arsand, R. B. Hoff, F. Barreto, and T. M. Pizzolato, "High-throughput method for the determination of residues of $\beta$-lactam antibiotics in bovine milk by LCMS/MS," Food Additives and Contaminants - Part A Chemistry, Analysis, Control, Exposure and Risk Assessment, vol. 32, no. 12, pp. 1992-2001, 2015.

[10] Z. Zhao, Y. Zhang, Y. Xuan et al., "Ion-exchange solid-phase extraction combined with liquid chromatography-tandem mass spectrometry for the determination of veterinary drugs in organic fertilizers," Journal of Chromatography B: Analytical Technologies in the Biomedical and Life Sciences, vol. 1022, pp. 281-289, 2016.

[11] M. Kamalabadi, A. Mohammadi, and N. Alizadeh, "Polypyrrole nanowire as an excellent solid phase microextraction fiber for bisphenol A analysis in food samples followed by ion mobility spectrometry," Talanta, vol. 156-157, pp. 147-153, 2016.

[12] A. Speltini, M. Sturini, F. Maraschi, S. Viti, D. Sbarbada, and A. Profumo, "Fluoroquinolone residues in compost by green enhanced microwave-assisted extraction followed by ultra performance liquid chromatography tandem mass spectrometry," Journal of Chromatography A, vol. 1410, pp. 44-50, 2015.

[13] R. B. Hoff, T. M. Pizzolato, M. D. C. R. Peralba, M. S. Díaz-Cruz, and D. Barceló, "Determination of sulfonamide antibiotics and metabolites in liver, muscle and kidney samples by pressurized liquid extraction or ultrasound-assisted extraction followed by liquid chromatography-quadrupole linear ion trap-tandem mass spectrometry (HPLC-QqLIT-MS/MS)," Talanta, vol. 134, pp. 768-778, 2015.

[14] S. J. Lehotay, "QuEChERS sample preparation approach for mass spectrometric analysis of pesticide residues in foods," Methods in Molecular Biology, vol. 747, pp. 65-91, 2011.

[15] T. Anumol, S. J. Lehotay, J. Stevens, and J. Zweigenbaum, "Comparison of veterinary drug residue results in animal tissues by ultrahigh-performance liquid chromatography coupled to triple quadrupole or quadrupole-time-of-flight tandem mass spectrometry after different sample preparation methods, including use of a commercial lipid removal product," Analytical and Bioanalytical Chemistry, vol. 409, no. 10, pp. 2639-2653, 2017.

[16] L. Han, Y. Sapozhnikova, and S. J. Lehotay, "Streamlined sample cleanup using combined dispersive solid-phase extraction and in-vial filtration for analysis of pesticides and environmental pollutants in shrimp," Analytica Chimica Acta, vol. 827, pp. 4046, 2014.

[17] B. Kinsella, S. J. Lehotay, K. Mastovska, A. R. Lightfield, A. Furey, and M. Danaher, "New method for the analysis of flukicide and other anthelmintic residues in bovine milk and liver using liquid chromatography-tandem mass spectrometry," Analytica Chimica Acta, vol. 637, no. 1-2, pp. 196-207, 2009.

[18] Y. Wang, J. Zhang, X. Huang, and D. Yuan, "Preparation of stir cake sorptive extraction based on polymeric ionic liquid for the enrichment of benzimidazole anthelmintics in water, honey and milk samples," Analytica Chimica Acta, vol. 840, pp. 33-41, 2014.

[19] M. Whelan, B. Kinsella, A. Furey et al., "Determination of anthelmintic drug residues in milk using ultra high performance liquid chromatography-tandem mass spectrometry with rapid polarity switching," Journal of Chromatography A, vol. 1217, no. 27, pp. 4612-4622, 2010.

[20] J. Domínguez-álvarez, M. Mateos-Vivas, D. García-Gómez, E. Rodríguez-Gonzalo, and R. Carabias-Martínez, "Capillary electrophoresis coupled to mass spectrometry for the determination of anthelmintic benzimidazoles in eggs using a QuEChERS with 
preconcentration as sample treatment," Journal of Chromatography A, vol. 1278, pp. 166-174, 2013.

[21] A. Gadaj, V. Di Lullo, H. Cantwell, M. McCormack, A. Furey, and M. Danaher, "Determination of nitroimidazole residues in aquaculture tissue using ultra high performance liquid chromatography coupled to tandem mass spectrometry," Journal of Chromatography B: Analytical Technologies in the Biomedical and Life Sciences, vol. 960, pp. 105-115, 2014.

[22] A. Posyniak, J. Zmudzki, and K. Mitrowska, "Dispersive solidphase extraction for the determination of sulfonamides in chicken muscle by liquid chromatography," Journal of Chromatography A, vol. 1087, no. 1-2, pp. 259-264, 2005.

[23] Y.-G. Zhao, L.-X. Zhou, S.-D. Pan, P.-P. Zhan, X.-H. Chen, and M.-C. Jin, "Fast determination of 22 sulfonamides from chicken breast muscle using core-shell nanoring amino-functionalized superparamagnetic molecularly imprinted polymer followed by liquid chromatography-tandem mass spectrometry," Journal of Chromatography A, vol. 1345, pp. 17-28, 2014.

[24] A. V. Herrera-Herrera, L. M. Ravelo-Pérez, J. HernándezBorges, M. M. Afonso, J. A. Palenzuela, and M. Á. RodríguezDelgado, "Oxidized multi-walled carbon nanotubes for the dispersive solid-phase extraction of quinolone antibiotics from water samples using capillary electrophoresis and large volume sample stacking with polarity switching," Journal of Chromatography $A$, vol. 1218, no. 31, pp. 5352-5361, 2011.

[25] W.-H. Tsai, T.-C. Huang, J.-J. Huang, Y.-H. Hsue, and H.-Y. Chuang, "Dispersive solid-phase microextraction method for sample extraction in the analysis of four tetracyclines in water and milk samples by high-performance liquid chromatography with diode-array detection," Journal of Chromatography A, vol. 1216, no. 12, pp. 2263-2269, 2009.

[26] M. Ghorbani, M. Chamsaz, and G. H. Rounaghi, "Ultrasoundassisted magnetic dispersive solid-phase microextraction: A novel approach for the rapid and efficient microextraction of naproxen and ibuprofen employing experimental design with high-performance liquid chromatography," Journal of Separation Science, vol. 39, no. 6, pp. 1082-1089, 2016.

[27] A. Rúbies, L. Guo, F. Centrich, and M. Granados, "Analysis of non-steroidal anti-inflammatory drugs in milk using QuEChERS and liquid chromatography coupled to mass spectrometry: triple quadrupole versus Q-Orbitrap mass analyzers," Analytical and Bioanalytical Chemistry, vol. 408, no. 21, pp. 5769-5778, 2016.

[28] L. Xiong, Y.-Q. Gao, W.-H. Li, X.-L. Yang, and S. P. Shimo, "Simple and sensitive monitoring of $\beta 2$-agonist residues in meat by liquid chromatography-tandem mass spectrometry using a QuEChERS with preconcentration as the sample treatment," Meat Science, vol. 105, pp. 96-107, 2015.

[29] N. Dorival-García, A. Junza, A. Zafra-Gómez, D. Barrón, and A. Navalón, "Simultaneous determination of quinolone and $\beta$ lactam residues in raw cow milk samples using ultrasoundassisted extraction and dispersive-SPE prior to UHPLC-MS/MS analysis," Food Control, vol. 60, pp. 382-393, 2016.

[30] I. S. Ibarra, J. A. Rodriguez, M. E. Páez-Hernández, E. M. Santos, and J. M. Miranda, "Determination of quinolones in milk samples using a combination of magnetic solid-phase extraction and capillary electrophoresis," Electrophoresis, vol. 33, no. 13, pp. 2041-2048, 2012.

[31] I. S. Ibarra, J. A. Rodriguez, J. M. Miranda, M. Vega, and E. Barrado, "Magnetic solid phase extraction based on phenyl silica adsorbent for the determination of tetracyclines in milk samples by capillary electrophoresis," Journal of Chromatography A, vol. 1218, no. 16, pp. 2196-2202, 2011.
[32] X.-Z. Hu, M.-L. Chen, Q. Gao, Q.-W. Yu, and Y.-Q. Feng, "Determination of benzimidazole residues in animal tissue samples by combination of magnetic solid-phase extraction with capillary zone electrophoresis," Talanta, vol. 89, pp. 335341, 2012.

[33] E. M. Reyes-Gallardo, R. Lucena, S. Cárdenas, and M. Valcárcel, "Dispersive micro-solid phase extraction of bisphenol A from milk using magnetic nylon 6 composite and its final determination by HPLC-UV," Microchemical Journal, vol. 124, pp. 751-756, 2016.

[34] Y. Hu, Y. Li, R. Liu, W. Tan, and G. Li, "Magnetic molecularly imprinted polymer beads prepared by microwave heating for selective enrichment of $\beta$-agonists in pork and pig liver samples," Talanta, vol. 84, no. 2, pp. 462-470, 2011.

[35] J. Wang, Z. Chen, Z. Li, and Y. Yang, "Magnetic nanoparticles based dispersive micro-solid-phase extraction as a novel technique for the determination of estrogens in pork samples," Food Chemistry, vol. 204, pp. 135-140, 2016.

[36] Q. Gao, D. Luo, J. Ding, and Y.-Q. Feng, "Rapid magnetic solidphase extraction based on magnetite/silica/poly(methacrylic acid-co-ethylene glycol dimethacrylate) composite microspheres for the determination of sulfonamide in milk samples," Journal of Chromatography A, vol. 1217, no. 35, pp. 5602-5609, 2010.

[37] Y.-F. Ying, Y.-L. Wu, Y. Wen, T. Yang, X.-Q. Xu, and Y.-Z. Wang, "Simultaneous determination of six resorcylic acid lactones in feed using liquid chromatography-tandem mass spectrometry and multi-walled carbon nanotubes as a dispersive solid phase extraction sorbent," Journal of Chromatography A, vol. 1307, pp. 41-48, 2013.

[38] Y.-L. Wu, R.-X. Chen, Y. Xue, T. Yang, J. Zhao, and Y. Zhu, "Simultaneous determination of amantadine, rimantadine and memantine in chicken muscle using multi-walled carbon nanotubes as a reversed-dispersive solid phase extraction sorbent," Journal of Chromatography B: Analytical Technologies in the Biomedical and Life Sciences, vol. 965, pp. 197-205, 2014.

[39] A. V. Herrera-Herrera, J. Hernández-Borges, M. M. Afonso, J. A. Palenzuela, and M. Á. Rodríguez-Delgado, "Comparison between magnetic and non magnetic multi-walled carbon nanotubes-dispersive solid-phase extraction combined with ultra-high performance liquid chromatography for the determination of sulfonamide antibiotics in water samples," Talanta, vol. 116, pp. 695-703, 2013.

[40] M. L. Castillo-García, M. P. Aguilar-Caballos, and A. GómezHens, "A europium- and terbium-coated magnetic nanocomposite as sorbent in dispersive solid phase extraction coupled with ultra-high performance liquid chromatography for antibiotic determination in meat samples," Journal of Chromatography A, vol. 1425, pp. 73-80, 2015.

[41] M. Anastassiades, S. J. Lehotay, D. Stajnbaher, and F. J. Schenck, "Fast and easy multiresidue method employing acetonitrile extraction/partitioning and "dispersive solid-phase extraction" for the determination of pesticide residues in produce," Journal of AOAC International, vol. 86, no. 2, pp. 412-431, 2003.

[42] M. R. Jamali, A. Firouzjah, and R. Rahnama, "Solvent-assisted dispersive solid phase extraction," Talanta, vol. 116, pp. 454-459, 2013.

[43] C. Cháfer-Pericás, Á. Balaguer, Á. Maquieira, and R. Puchades, "Dispersive solid-phase extraction and immunoassay with internal reference calibration using fatty acid-coated inorganic fluorescent nanoparticles," Analytical Biochemistry, vol. 432, no. 1, pp. 31-37, 2013. 
[44] C. Díez, W. A. Traag, P. Zommer, P. Marinero, and J. Atienza, "Comparison of an acetonitrile extraction/partitioning and "dispersive solid-phase extraction" method with classical multiresidue methods for the extraction of herbicide residues in barley samples," Journal of Chromatography A, vol. 1131, no. 12, pp. 11-23, 2006.

[45] C. K. Fagerquist, A. R. Lightfield, and S. J. Lehotay, "Confirmatory and quantitative analysis of $\beta$-lactam antibiotics in bovine kidney tissue by dispersive solid-phase extraction and liquid chromatography-tandem mass spectrometry," Analytical Chemistry, vol. 77, no. 5, pp. 1473-1482, 2005.

[46] F. Plössl, M. Giera, and F. Bracher, "Multiresidue analytical method using dispersive solid-phase extraction and gas chromatography/ion trap mass spectrometry to determine pharmaceuticals in whole blood," Journal of Chromatography A, vol. 1135, no. 1, pp. 19-26, 2006.

[47] C. L. Silva, N. Haesen, and J. S. Câmara, "A new and improved strategy combining a dispersive-solid phase extraction-based multiclass method with ultra high pressure liquid chromatography for analysis of low molecular weight polyphenols in vegetables," Journal of Chromatography A, vol. 1260, pp. 154-163, 2012.

[48] P. Deme, T. Azmeera, B. L. A. Prabhavathi Devi, P. R. Jonnalagadda, R. B. N. Prasad, and U. V. R. Vijaya Sarathi, "An improved dispersive solid-phase extraction clean-up method for the gas chromatography-negative chemical ionisation tandem mass spectrometric determination of multiclass pesticide residues in edible oils," Food Chemistry, vol. 142, pp. 144-151, 2014.

[49] F. J. Lara, A. M. García-Campaña, C. Neusüss, and F. AlésBarrero, "Determination of sulfonamide residues in water samples by in-line solid-phase extraction-capillary electrophoresis," Journal of Chromatography A, vol. 1216, no. 15, pp. 3372-3379, 2009.

[50] M. M. Aguilera-Luiz, J. L. M. Vidal, R. Romero-González, and A. G. Frenich, "Multi-residue determination of veterinary drugs in milk by ultra-high-pressure liquid chromatography-tandem mass spectrometry," Journal of Chromatography A, vol. 1205, no. 1-2, pp. 10-16, 2008.

[51] A. Garrido Frenich, M. D. M. Aguilera-Luiz, J. L. Martínez Vidal, and R. Romero-González, "Comparison of several extraction techniques for multiclass analysis of veterinary drugs in eggs using ultra-high pressure liquid chromatography-tandem mass spectrometry," Analytica Chimica Acta, vol. 661, no. 2, pp. 150-160, 2010.

[52] E. M. Malone, C. T. Elliott, D. G. Kennedy, and L. Regan, "Rapid confirmatory method for the determination of sixteen synthetic growth promoters and bisphenol A in bovine milk using dispersive solid-phase extraction and liquid chromatographytandem mass spectrometry," Journal of Chromatography B: Analytical Technologies in the Biomedical and Life Sciences, vol. 878, no. 15-16, pp. 1077-1084, 2010.

[53] H.-Y. Liu, S.-L. Lin, and M.-R. Fuh, "Determination of chloramphenicol, thiamphenicol and florfenicol in milk and honey using modified QuEChERS extraction coupled with polymeric monolith-based capillary liquid chromatography tandem mass spectrometry," Talanta, vol. 150, pp. 233-239, 2016.

[54] J. F. Huertas-Pérez, N. Arroyo-Manzanares, L. Havlíková, L. Gámiz-Gracia, P. Solich, and A. M. García-Campaña, "Method optimization and validation for the determination of eight sulfonamides in chicken muscle and eggs by modified QuEChERS and liquid chromatography with fluorescence detection," Journal of Pharmaceutical and Biomedical Analysis, vol. 124, pp. 261-266, 2016.
[55] L. Geis-Asteggiante, S. J. Lehotay, A. R. Lightfield, T. Dutko, C. $\mathrm{Ng}$, and $\mathrm{L}$. Bluhm, "Ruggedness testing and validation of a practical analytical method for $>100$ veterinary drug residues in bovine muscle by ultrahigh performance liquid chromatography-tandem mass spectrometry," Journal of Chromatography A, vol. 1258, pp. 43-54, 2012.

[56] A. Wilkowska and M. Biziuk, "Determination of pesticide residues in food matrices using the QuEChERS methodology," Food Chemistry, vol. 125, no. 3, pp. 803-812, 2011.

[57] W.-H. Tsai, H.-Y. Chuang, H.-H. Chen et al., "Application of dispersive liquid-liquid microextraction and dispersive microsolid-phase extraction for the determination of quinolones in swine muscle by high-performance liquid chromatography with diode-array detection," Analytica Chimica Acta, vol. 656, no. 1-2, pp. 56-62, 2009.

[58] E. Kazemi, S. Dadfarnia, A. M. Haji Shabani, A. Abbasi, M. R. Rashidian Vaziri, and A. Behjat, "Iron oxide functionalized graphene oxide as an efficient sorbent for dispersive microsolid phase extraction of sulfadiazine followed by spectrophotometric and mode-mismatched thermal lens spectrometric determination," Talanta, vol. 147, pp. 561-568, 2016.

[59] K. Aguilar-Arteaga, J. A. Rodríguez, and E. Barrado, "Magnetic solids in analytical chemistry: a review," Analytica Chimica Acta, vol. 674, no. 2, pp. 157-165, 2010.

[60] I. S. Ibarra, J. M. Miranda, J. A. Rodriguez, C. Nebot, and A. Cepeda, "Magnetic solid phase extraction followed by highperformance liquid chromatography for the determination of sulphonamides in milk samples," Food Chemistry, vol. 157, pp. 511-517, 2014.

[61] J. L. D. O. Arias, C. Rombaldi, S. S. Caldas, and E. G. Primel, "Alternative sorbents for the dispersive solid-phase extraction step in quick, easy, cheap, effective, rugged and safe method for extraction of pesticides from rice paddy soils with determination by liquid chromatography tandem mass spectrometry," Journal of Chromatography A, vol. 1360, pp. 66-75, 2014.

[62] I. S. Ibarra, J. A. Rodriguez, C. A. Galán-Vidal, A. Cepeda, and J. M. Miranda, "Magnetic solid phase extraction applied to food analysis," Journal of Chemistry, vol. 2015, Article ID 919414, 2015.

[63] L. Chen, X. Wang, W. Lu, X. Wu, and J. Li, "Molecular imprinting: perspectives and applications," Chemical Society Reviews, vol. 45, pp. 2137-2211, 2016.

[64] G. Wulff and A. Sarhan, "The use of polymers with enzymeanalogous structures for the resolution of racemates," vol. 11, pp. 341-344, 1972.

[65] P. A. G. Cormack and A. Z. Elorza, "Molecularly imprinted polymers: Synthesis and characterisation," Journal of Chromatography B: Analytical Technologies in the Biomedical and Life Sciences, vol. 804, no. 1, pp. 173-182, 2004.

[66] G. Z. Kyzas, D. N. Bikiaris, and N. K. Lazaridis, "Selective separation of basic and reactive dyes by molecularly imprinted polymers (MIPs)," Chemical Engineering Journal, vol. 149, no. 13, pp. 263-272, 2009.

[67] M. C. Cela-Pérez, A. Lasagabáster-Latorre, M. J. Abad-López, J. M. López-Vilariño, and M. V. Gónzalez-Rodríguez, "A study of competitive molecular interaction effects on imprinting of molecularly imprinted polymers," Vibrational Spectroscopy, vol. 65, pp. 74-83, 2013.

[68] N. Gilart, R. M. Marcé, F. Borrull, and N. Fontanals, "New coatings for stir-bar sorptive extraction of polar emerging organic contaminants," TrAC - Trends in Analytical Chemistry, vol. 54, pp. 11-23, 2014. 
[69] A. Lasagabáster-Latorre, M. C. Cela-Pérez, S. FernándezFernández et al., "Insight into BPA-4-vinylpyridine interactions in molecularly imprinted polymers using complementary spectroscopy techniques," Materials Chemistry and Physics, vol. 141, no. 1, pp. 461-476, 2013.

[70] A. Anene, K. Hosni, Y. Chevalier, R. Kalfat, and S. Hbaieb, "Molecularly imprinted polymer for extraction of patulin in apple juice samples," Food Control, vol. 70, pp. 90-95, 2016.

[71] M. X. Feng, G. N. Wang, K. Yang, H. Z. Liu, and J. P. Wang, "Molecularly imprinted polymer-high performance liquid chromatography for the determination of tetracycline drugs in animal derived foods," Food Control, vol. 69, pp. 171-176, 2016.

[72] R. Zhu, W. Zhao, M. Zhai et al., "Molecularly imprinted layercoated silica nanoparticles for selective solid-phase extraction of bisphenol A from chemical cleansing and cosmetics samples," Analytica Chimica Acta, vol. 658, no. 2, pp. 209-216, 2010.

[73] Y. Hu, R. Liu, Y. Li, and G. Li, "Investigation of ractopamineimprinted polymer for dispersive solid-phase extraction of trace $\beta$-agonists in pig tissues," Journal of Separation Science, vol. 33, no. 13, pp. 2017-2025, 2010.

[74] R. J. Ansell and K. Mosbach, "Magnetic molecularly imprinted polymer beads for drug radioligand binding assay," Analyst, vol. 123, no. 7, pp. 1611-1616, 1998.

[75] L. Chen, J. Liu, Q. Zeng et al., "Preparation of magnetic molecularly imprinted polymer for the separation of tetracycline antibiotics from egg and tissue samples," Journal of Chromatography A, vol. 1216, no. 18, pp. 3710-3719, 2009.

[76] L. Chen, X. Zhang, Y. Xu et al., "Determination of fluoroquinolone antibiotics in environmental water samples based on magnetic molecularly imprinted polymer extraction followed by liquid chromatography-tandem mass spectrometry," Analytica Chimica Acta, vol. 662, no. 1, pp. 31-38, 2010.

[77] W. Chai, H. Wang, Y. Zhang, and G. Ding, "Preparation of polydopamine-coated magnetic nanoparticles for dispersive solid-phase extraction of water-soluble synthetic colorants in beverage samples with HPLC analysis," Talanta, vol. 149, pp. 1320, 2016.

[78] A. A. K. Asgharinezhad and H. Ebrahimzadeh, "Poly(2-aminobenzothiazole)-coated graphene oxide/magnetite nanoparticles composite as an efficient sorbent for determination of nonsteroidal anti-inflammatory drugs in urine sample," Journal of chromatography. A, vol. 1435, pp. 18-29, 2016.

[79] F. Qiao and M. Wang, "Preparation of selective magnetic dispersive solid-phase sorbent and its application for recognition clenbuterol from bovine urine," Journal of Chromatography B: Analytical Technologies in the Biomedical and Life Sciences, vol. 1017-1018, pp. 18-27, 2016.

[80] H.-B. He, C. Dong, B. Li et al., "Fabrication of enrofloxacin imprinted organic-inorganic hybrid mesoporous sorbent from nanomagnetic polyhedral oligomeric silsesquioxanes for the selective extraction of fluoroquinolones in milk samples," Journal of Chromatography A, vol. 1361, pp. 23-33, 2014.

[81] H.-B. Zheng, J.-Z. Mo, Y. Zhang et al., "Facile synthesis of magnetic molecularly imprinted polymers and its application in magnetic solid phase extraction for fluoroquinolones in milk samples," Journal of Chromatography A, vol. 1329, pp. 17-23, 2014.

[82] F. Qiao and H. Sun, "Simultaneous extraction of enrofloxacin and ciprofloxacin from chicken tissue by molecularly imprinted matrix solid-phase dispersion," Journal of Pharmaceutical and Biomedical Analysis, vol. 53, no. 3, pp. 795-798, 2010.
[83] X. Kong, R. Gao, X. He, L. Chen, and Y. Zhang, "Synthesis and characterization of the core-shell magnetic molecularly imprinted polymers $\left(\mathrm{Fe}_{3} \mathrm{O}_{4} @ \mathrm{MIPs}\right)$ adsorbents for effective extraction and determination of sulfonamides in the poultry feed," Journal of Chromatography A, vol. 1245, pp. 8-16, 2012.

[84] Z. K. Sarkar and F. K. Sarkar, "Synthesis and magnetic properties investigations of Fe3O4 nanoparticles," vol. 7, pp. 197-200, 2011.

[85] V. V. Tolmacheva, V. V. Apyari, A. A. Furletov, S. G. Dmitrienko, and Y. A. Zolotov, "Facile synthesis of magnetic hypercrosslinked polystyrene and its application in the magnetic solidphase extraction of sulfonamides from water and milk samples before their HPLC determination," Talanta, vol. 152, pp. 203210, 2016.

[86] Z. Zhang, Y. Wu, X. Li et al., "Multi-class method for the determination of nitroimidazoles, nitrofurans, and chloramphenicol in chicken muscle and egg by dispersive-solid phase extraction and ultra-high performance liquid chromatography-tandem mass spectrometry," Food Chemistry, vol. 217, pp. 182-190, 2017.

[87] B. Suárez, B. Santos, B. M. Simonet, S. Cárdenas, and M. Valcárcel, "Solid-phase extraction-capillary electrophoresismass spectrometry for the determination of tetracyclines residues in surface water by using carbon nanotubes as sorbent material," Journal of Chromatography A, vol. 1175, no. 1, pp. 127132, 2007.

[88] R. P. Lopes, R. C. Reyes, R. Romero-González, A. G. Frenich, and J. L. M. Vidal, "Development and validation of a multiclass method for the determination of veterinary drug residues in chicken by ultra high performance liquid chromatographytandem mass spectrometry," Talanta, vol. 89, pp. 201-208, 2012.

[89] B. Kinsella, P. Byrne, H. Cantwell, M. McCormack, A. Furey, and M. Danaher, "Determination of the new anthelmintic monepantel and its sulfone metabolite in milk and muscle using a UHPLC-MS/MS and QuEChERS method," Journal of Chromatography B: Analytical Technologies in the Biomedical and Life Sciences, vol. 879, no. 31, pp. 3707-3713, 2011.

[90] G. Stubbings and T. Bigwood, "The development and validation of a multiclass liquid chromatography tandem mass spectrometry (LC-MS/MS) procedure for the determination of veterinary drug residues in animal tissue using a quechers (Quick , Easy, Cheap, Effective, Rugged and Safe) approach," Analytica Chimica Acta, vol. 637, no. 1-2, pp. 68-78, 2009.

[91] A. H. Shendy, M. A. Al-Ghobashy, S. A. Gad Alla, and H. M. Lotfy, "Development and validation of a modified QuEChERS protocol coupled to LC-MS/MS for simultaneous determination of multi-class antibiotic residues in honey," Food Chemistry, vol. 190, pp. 982-989, 2016.

[92] G. R. Silva, J. A. Lima, L. F. Souza et al., "Multiresidue method for identification and quantification of avermectins, benzimidazoles and nitroimidazoles residues in bovine muscle tissue by ultra-high performance liquid chromatography tandem mass spectrometry (UHPLC-MS/MS) using a QuEChERS approach," Talanta, vol. 171, pp. 307-320, 2017.

[93] R. P. Lopes, R. C. Reyes, R. Romero-González, J. L. M. Vidal, and A. G. Frenich, "Multiresidue determination of veterinary drugs in aquaculture fish samples by ultra high performance liquid chromatography coupled to tandem mass spectrometry," Journal of Chromatography B: Analytical Technologies in the Biomedical and Life Sciences, vol. 895-896, pp. 39-47, 2012.

[94] G.-J. Zhang, B.-H. Fang, Y.-H. Liu et al., "Development of a multi-residue method for fast screening and confirmation of 20 prohibited veterinary drugs in feedstuffs by liquid chromatography tandem mass spectrometry," Journal of Chromatography 
B: Analytical Technologies in the Biomedical and Life Sciences, vol. 936, pp. 10-17, 2013.

[95] M. Lombardo-Agüí, A. M. García-Campaña, L. Gámiz-Gracia, and C. Cruces-Blanco, "Determination of quinolones of veterinary use in bee products by ultra-high performance liquid chromatography-tandem mass spectrometry using a QuEChERS extraction procedure," Talanta, vol. 93, pp. 193-199, 2012.

[96] G. Islas, J. A. Rodríguez, M. E. Páez-Hernández, S. CoronaAvendaño, A. Rojas-Hernández, and E. Barrado, "Dispersive solid-phase extraction based on butylamide silica for the determination of sulfamethoxazole in milk samples by capillary electrophoresis," Journal of Liquid Chromatography and Related Technologies, vol. 39, no. 14, pp. 658-665, 2016. 

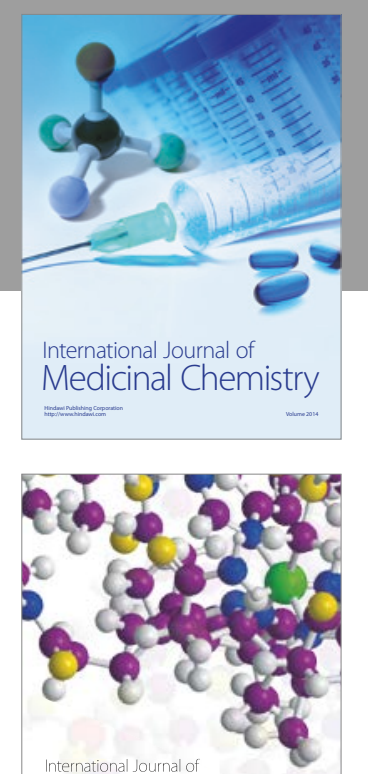

Carbohydrate Chemistry

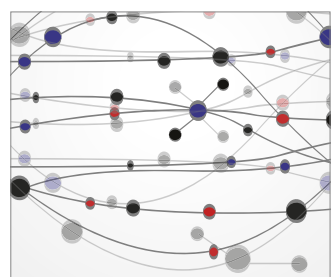

The Scientific World Journal
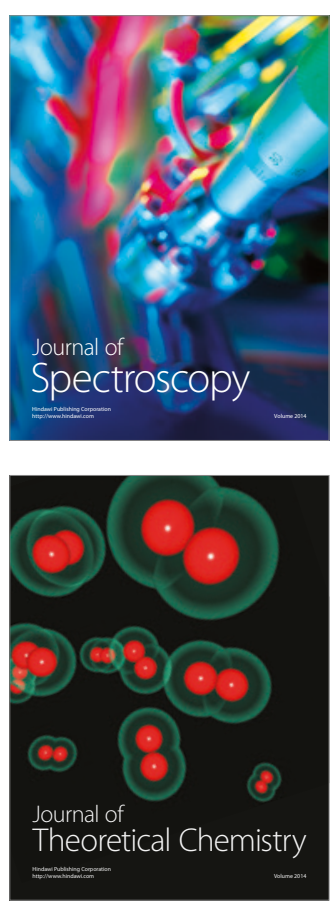
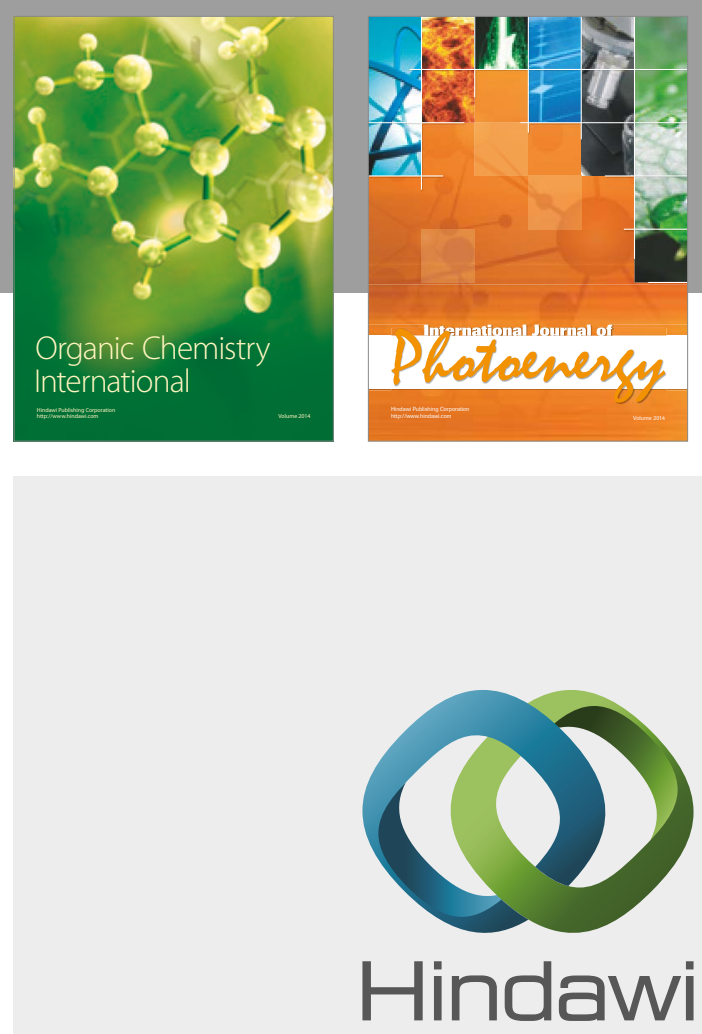

Submit your manuscripts at

https://www.hindawi.com

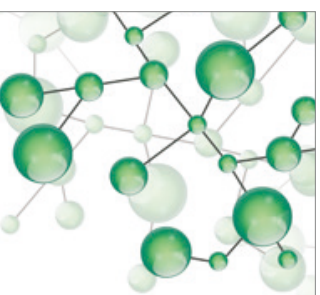

International Journal of

Inorganic Chemistry

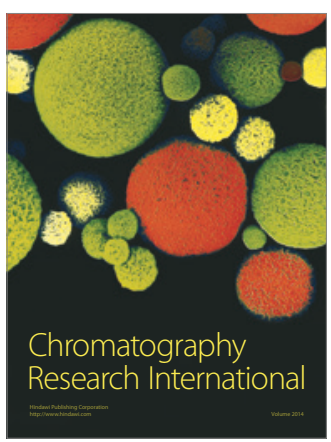

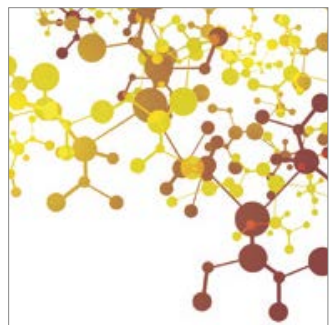

Applied Chemistry
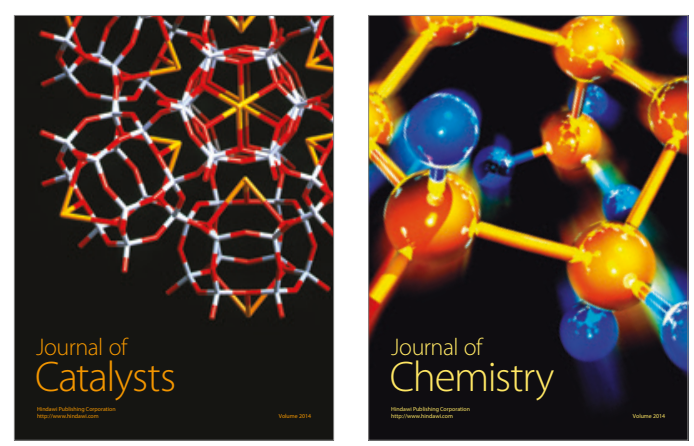
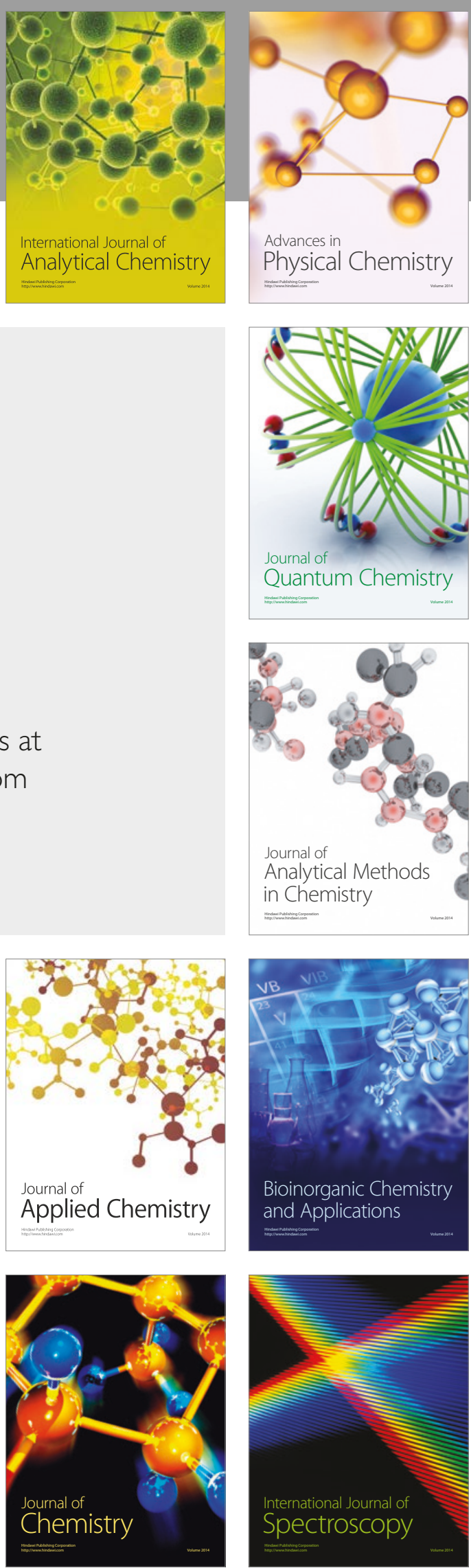